been directed towards the development of a gravimetric sampler for measurement of respirable dust, and the opinion is expressed that measuring the mass concentration of respirable dust may prove more useful and convenient than the present practice of measuring particle-number concentrations. Altogether a variety of topics is covered within the sections of the report and many of these are of scientific and technological interest to a wide range of industries in addition to the mining industry.

\section{The International Journal of Heat and Mass Transfer}

THE wide application of heat and mass transfer, including almost every form of engineering, chemistry and physics, has made it inevitable that much valuable information has hitherto appeared in specialized journals which pass unnoticed by workers in other fields, who might well find use for such data. The very large number of papers now published indeed makes it impossible to examine all the journals containing such subject-matter. The addition of a new monthly journal, published by the Pergamon Press, and entitled The International Journal of Heat and Mass Transfer, will be welcomed by all engaged in such work (1, No. 1; June 1960. Pp. 114. Subscription rates: $(A)$ for Libraries, Government Establishments, Research Laboratories, etc., £7 (20 dollars) per vol.; $(B)$ for individuals who place their orders directly with the publisher and certify that the journal is for their personal use, $£ 55 s$. (15 dollars) per annum). Six distinguished editors drawn from Great Britain, the United States, U.S.S.R. and Germany, assisted by some fifty advisers representing major academic and industrial concerns from all over the world, should ensure a truly international journal with a succession of papers of high standard. The first issue contains an editorial article and ten papers, two of which are in German, one in French, the remainder in English; all papers have an abstract in English, French, German and Russian. There is also a "Bibliography of Heat Transfer", presumably of publications written in the past few years only, though this is not stated. Research workers already familiar with advanced concepts will find the contents of the most value. It is to be hoped that the editors will from time to time include fundamental but more elementary articles for the benefit of less erudite students, such as those in their first year of Ph.D. work.

\section{Bibliography of Research at Oak Ridge National Laboratory}

A LIST of articles by members of the staff of the Oak Ridge National Laboratory (operated by the Union Carbide Corporation for the United States Atomic Energy Commission) published during 1959 in technical journals has been issued by the Laboratory, and requests for reprints where available, as indicated by the prefix $R$, should be addressed to the Central Research Library at the Laboratory (Pp.v + 84. Oak Ridge, Tennessee : Oak RidgeNational Laboratory, U.S. Atomic Energy Cornmission, 1960). The articles are arranged alphabetically by author under nine divisions : biology ; chemistry ; general ; health physics; instrumentation; mathematics; metallurgy and materials; physics; and technology. There is an accompanying list of reports issued by the Laboratory, and these, except when indicated as "Not for sale", should be ordered through the Office of Technical Services, Department of Commerce, Washington 25, D.C. A third list, similarly arranged, records the titles of papers presented at scientific meetings, and requests for information regarding these papers should be addressed to the authors concerned. Titles of eighteen theses completed at the Laboratory during the year are given in a fourth list, alphabetical by author, and finally there is a list of sixty-eight inventions disclosed during the year.

\section{Research into Electricity Supply}

As a postscript to an article on the supply of electricity in Great Britain, Arthur Palmer suggests unified areas where research could be carried out (Research Applied in Industry, 13, No. 9 : September 1960). These include investigations into funda. mental questions of electricity production and use : for example, ways and means of escaping the limitations of the thermodynamic cycle and methods of solving the outstanding energy storage problem; investigations into reductions of cost in all the fields of generation, transmission, distribution and utilization-this is primarily a scientific and engineering matter, but it must occasionally take account of psychology or even sociology; investigations into techniques for reducing the social nuisance of electrical processes-in an island packed with more and more human beings demanding simultaneously the often mutually contradictory ends of higher and better standards, this is no easy task ; and investiga. tions into the possibility of maintaining human interest in an industrial environment which when ideally organized and arranged will record the almost effortless glide of electrons from genesis to consummation.

\section{Poison Sprays and Wild Life}

A JoInt Committee of the Royal Society for the Protection of Birds and the British Trust for Ornithology has been formed under the chairmanship of Mr. S. Cramp to study the effect of toxic chemicals on birds. The Committee is anxious to obtain evidence of kills of birds due to agricultural chemicals used in sprays or in the form of seed dressings. The basic information needed is the date and locality of the kills, the species and number of birds affected and the chemical used. The Committee would appreciate prompt notification of birds the death of which is thought to be due to agricultural chemicals, so that if necessary corpses may be collected for chemical analysis. Information should be sent to the secretary of the Committee, Mr. P. J. Conder, Royal Society for the Protection of Birds, 25 Fecleston Square, London, S.W.1.

\section{Insulin}

A RECENT issue of the British Medical Bulletin deals with insulin in its varied aspects (16, No. 3; September 1960). Prof. Charles H. Best describes his pioneer work with Banting and developments which have occurred during the past forty years. 'This is followed by an account by Dr. F. Sanger of the chemistry of insulin based on his Nobel Prize Lecture. Other articles include one by Dr. Ieun Harris on the chemistry of pituitary polypeptide hormones ; methods of insulin assay by G. A. Stewart ; insulin antibodies by Dr. P. H. Wright; the action of insulin on carbohydrate metabolism by Dr. R. B. 